Revista Brasileira de Farmacognosia Brazilian Journal of Pharmacognosy 22(5): 1018-1023, Sep./Oct. 2012

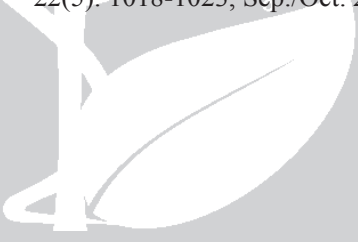

Article

Received 18 Jan 2012

Accepted 15 Apr 2012

Available online 21 Jun 2012

Keywords:

cyclopentenedione

Leishmania amazonensis

leishmanicidal activity

Piper carniconnectivum

Piperaceae

ISSN 0102-695X

http://dx.doi.org/10.1590/S0102-

$695 \times 2012005000086$

\section{The leishmanicidal activity of a cyclopentenedione derivative isolated from the roots of a native Amazonian pepper (Piper carniconnectivum)}

\author{
Hilda Paes-Gonçalves, ${ }^{1,2}$ Valdir A. Facundo, ${ }^{2}$ Delvânia M. F. \\ Santos, ${ }^{1}$ Ana G. C. Silva, ${ }^{2}$ Laudir J. Ballico, ${ }^{2}$ Daniella K. S. \\ Lima, ${ }^{2}$ Rodrigo G. Stábeli, ${ }^{1,3}$ Izaltina Silva-Jardim ${ }^{*}, 1,4$
}

\author{
${ }^{1}$ Fundação Oswaldo Cruz, Fiocruz Rondônia, Brazil, \\ ${ }^{2}$ Laboratório de Química Orgânica, Núcleo de Ciências e Tecnologia, \\ Universidade Federal de Rondônia, Brazil, \\ ${ }^{3}$ Centro de Estudos de Biomoléculas Aplicadas a Medicina Prof. Dr. José \\ Roberto Giglio, Núcleo de Saúde, Universidade Federal de Rondônia, Brazil, \\ ${ }^{4}$ Laboratório de Cristalografia de Proteinas e Biologia Estrutural, Instituto de \\ Física de São Carlos, Universidade de São Paulo, Brazil.
}

\begin{abstract}
The Piper species chemistry has been widely investigated and the phytochemical analyses have led to the isolation of a number of active compounds like alkaloids, terpenes and flavones among others. The aim of this study was to evaluate the leishmanicidal activity of 2-[1-hydroxy-3-phenyl-(Z,2E)-2-propenylidene]-4methyl-4-cyclopentene-1,3-dione (DCPC), a cyclopentenedione derivative isolated from the roots of Piper carniconnectivum C. DC., Piperaceae. Leishmanicidal activity against Leishmania amazonensis promastigotes was assessed, and the risk to host cell was assessed by measuring the cytotoxicity to peritoneal macrophages from BALB/c mice in vitro. L. amazonensis promastigotes and host macrophages were cultured in the presence of $100,50,25,12.5$ and $6 \mu \mathrm{g} / \mathrm{mL}$ of the cyclopentenedione derivative for up to $96 \mathrm{~h}$. At the end of this period, the inhibitory concentrations (IC50) were compared with those from untreated cultures. The IC50 for promastigotes was $4.4 \mu \mathrm{g} / \mathrm{mL}$ after $96 \mathrm{~h}$ of treatment with the derivative. The $50 \%$ cytotoxic concentration (CC50) against murine peritoneal macrophages was $129 \mu \mathrm{g} / \mathrm{mL}$. These results indicate that DCPC is a promising molecule for the development of leishmanicidal drugs.
\end{abstract}

Introduction

Leishmaniasis is a group of parasitic diseases that affects two million people each year and is endemic in 98 countries and territories (WHO, 2010). Brazil is among the seven countries with the highest rates of cutaneous leishmaniasis and is one of the five countries in which almost all cases of visceral leishmaniasis occur (Singh et al., 2006; Gramiccia \& Gradoni, 2005).

Depending on the species of Leishmania, the disease can manifest as cutaneous leishmaniasis, mucocutaneous leishmaniasis or diffuse cutaneous leishmaniasis, which constitutes American Cutaneous Leishmaniasis (ACL). The most severe form of the disease, visceral leishmaniasis (VL), affects the lymphatic system and may lead to death if untreated (WHO, 2010; Herwaldt, 1999; Lucas et al., 1998).

The chemotherapeutics available for treating this disease are based on pentavalent antimony compounds, which have severe side effects in the heart, kidney, pancreas and liver, as well as reported cases of resistance (Oliveira et al., 2011; Croft \& Yardley, 2002). In cases where there are contraindications or resistance to antimony compounds, amphotericin B or pentamidine are used. However, the use of these alternatives is restricted due to their high toxicity and adverse side effects (Lima et al., 2007; Croft \& Combs, 2003; Amato et al., 2000).

In the search for new alternatives for the treatment of leishmaniasis, previous studies have focused on natural compounds extracted from animals and plants, which are effective against Leishmania and have reduced toxicity for human hosts (Ferreira et al., 2010; Calderon et al., 2009).

The genus Piper, which belongs to the Piperaceae family, is widespread in tropical and 
subtropical regions around the world. Many Piper species are used for curative purposes by different cultures (Bezerra et al., 2007). The history of the genus Piper, described by Parmar et al. (1997), describes the use of this species for the treatment of certain diseases in several different populations. In the Amazon region, several Piper species are used in phytotherapy. For example, $P$. maginatum is used for menstrual pains, snake bites and as a tonic for the liver and spleen, and $P$. tuberculatum is used as a sedative, an antidote against snake bites and to combat sexually transmitted diseases and urinary tract infections (Agra et al., 2007, 2008; Rodrigues et al., 2009). Leishmanicidal activity was recently reported from a cinnamic acid derivative (3-(3,4,5-trimethoxyphenyl) isolated from the fruit of P. tuberculatum plants (Ferreira et al., 2010). Dihydrochalcones isolated from $P$. elongates have also shown leishmanicidal activity (Hermoso et al., 2003). Phytochemical studies of the leaves and roots of P. carniconnectivum C. DC., Piperaceae, led to the discovery of volatile substances, including flavonoids and cyclopentenedione derivatives (Facundo et al., 2004, 2006).

The present study evaluated the leishmanicidal activity of the cyclopentenedione derivative 2-[1hydroxy-3-phenyl-(Z,2E)-2-propenylidene]-4-methyl-4cyclopentene-1,3-dione (1) (DCPC), isolated from roots of P. carniconnectivum (Facundo et al., 2004), against extracellular Leishmania amazonensis promastigotes. We also analyzed the cytotoxic activity of the compound in the peritoneal macrophages of $\mathrm{BALB} / \mathrm{c}$ mice.

\section{Materials and Methods}

\section{Plant material}

The cyclopentenedione derivative DCPC (2-[1-hydroxy-3-phenyl-(Z,2E)-2-propenylidene]-4methyl-4-cyclopentene-1,3-dione) (1) was isolated and identified from the roots of $P$. carniconnectivum C. DC., Piperaceae, following the methods of Facundo et al. (2004). Roots of Piper carniconnectivum were collected in Porto Velho, Rondônia, Brazil. The botanical identification (exsiccate number 211.718) was confirmed by Instituto Nacional de Pesquisas da Amazônia (INPA), Manaus, Brazil.

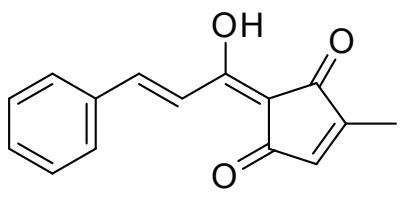

1

\section{In vitro leishmanicidal activity}

The leishmanicidal activity of the DCPC was evaluated by assessing the growth inhibition of promastigotes of Leishmania amazonensis PH8 reference strain (IFLA/BR/67/PH8). For these experiments, parasites $\left(5 \times 10^{5} / \mathrm{mL}\right)$ in the early stationary phase of growth were incubated at $24{ }^{\circ} \mathrm{C}$ for up to $96 \mathrm{~h}$ with concentrations of $100,50,25,12.5$ and $6 \mu \mathrm{g} / \mathrm{mL}$ of DCPC (dissolved in $0.3 \%$ ethanol). Parasite viability was determined daily by counting under an optical microscope with a magnification of 400x, using the dye erythrosine B ( $0.04 \%$ in phosphate buffered saline). The total number of living promastigotes in each sample was compared with the number of promastigotes in an untreated control. Pentamidine was used as reference drug. Each concentration was analyzed in duplicate and experiments were repeated three times.

\section{In vitro cytotoxicity}

To analyze the viability of the host cells after treatment with DCPC, we used the trypan blue exclusion test. Tests were performed on peritoneal macrophages obtained from $\mathrm{BALB} / \mathrm{c}$ mice from the Instituto de Pesquisas em Patologias Tropicais-IPEPATRO. The study was approved by the Animal Use Ethics Committee of IPEPATRO (registration No. 006/2008).

The $\mathrm{BALB} / \mathrm{c}$ mice were injected intraperitoneally with $2 \mathrm{~mL}$ of a sterile thioglycollate solution (3\%), following the method of Gordon et al. (1974). After four days, the animals were euthanized, and $5 \mathrm{~mL}$ of cold RPMI-1640 medium was injected into the peritoneal cavity; after a slight massage the medium was subsequently recovered. The cells obtained were washed and counted in a Neubauer hemocytometer. The peritoneal macrophages $\left(1 \times 10^{5} / \mathrm{mL}\right)$ were treated with $100,50,25,12.5$ and $6 \mu \mathrm{g} / \mathrm{mL}$ of DCPC and maintained for up to $96 \mathrm{~h}$ at $37^{\circ} \mathrm{C}$ and $5 \% \mathrm{CO}_{2}$. As a control, macrophages were incubated without DCPC in RPMI- 1640 and $0.3 \%$ ethanol.

The amount of cytotoxicity was evaluated after 24, 48 and 96 h of DCPC treatment. Cytotoxicity was assessed by adding $10 \mu \mathrm{L}$ of a trypan blue solution $(0.1 \%)$ to the cells, and the number of live and dead cells was counted from a sample of 100 cells under an optical microscope with 400x magnification. Cells stained blue were considered dead and live cells were considered to be birefringent.

\section{Statistical analyses}

Analysis of variance (ANOVA) followed by the NewMan-Keuls test was used to analyze the results $(\alpha \leq 0.05)$. 


\section{Results and discussion}

The cyclopentenediones belong to a relatively recently recognized class of substances that are composed of several compounds with a limited occurrence in nature (Li et al., 2006; Facundo \& BrazFilho, 2004). The activity and rarity of these compounds have generated great interest in understanding their biological activity and in the development of synthetic analogs. In this study, the leishmanicidal activity of DCPC, a cyclopentenedione derivative isolated from the roots of Piper carniconnectivum C. DC., Piperaceae, was evaluated.

The fungicidal activity of Coruscanone A, which is derived from the cyclopentenedione 2-methoxymethylenecyclopent-4-ene-1,3-dione, has been evaluated against Candida albicans and Cryptococcus neoformans. The activity of coruscanone A, which is isolated from the Peruvian pepper plant Piper coruscan, was comparable to or greater than that of amphotericin B. Coruscanone A also has a potent effect on fungal strains that are resistant to fluconazol, and it is therefore considered an alternative for the treatment of high risk immunocompromised patients and may also be of use as template for a new class of synthetic antifungal agents (Li et al., 2006; Babu et al., 2006). However, there have been no studies demonstrating an activity of cyclopentenediones against protozoa. Thus, the present study is the first to present the results of biological analysis of the activity of cyclopentenedione derivatives against Leishmania amazonensis.

In Brasil, Leishmania (leishmania) amazonensis is distributed mainly in the Amazon region, in areas of primary and secondary forests (States of Amazonas, Pará, Rondonia and southwest of Maranhão) (Coelho et al., 2011). It is one of the causative agents of localized cutaneous leishmaniasis and the only species responsible for diffuse cutaneous leishmaniasis (DCL). This species can also cause mucocutaneous or visceral leishmaniasis (Barral et al., 1991; Abreu-silva et al., 2003; Tolezano et al., 2007). The diffuse cutaneous leishmaniasis (DCL) is a rare form of cutaneous leishmaniasis that typically begins as localized and not ulcerated papules or nodules. In the DCL, amastigotes disseminate in the skin and produce nodules in several parts of the body such as the face and extremities (Morrison et al., 2009; Silveira et al., 2004; Barral et al., 1991). Although rare, DCL is an incapacitating disease and there is no satisfactory response to treatment (Zerpa et al., 2007). Since the treatment of most clinical forms of leishmaniasis is usually unsatisfactory and the drugs used are highly toxic, it is necessary to find novel compounds with potential leishmanicidal activity.

Facundo \& Braz-Filho (2004) suggested that DCPC was derived as a by-product of mevalonic acid and the shikimic pathway. This result was subsequently confirmed by Dias et al. (2005), who studied the potential relevance of synthetic cyclopentenedione derivatives to biological science, using the molecule 2-[1-hydroxy-3 phenyl-( $Z, 2 E)$-2-propenylidene $]$-4methyl-4-cyclopentene-1,3-dione isolated from Piper carniconnectivum as a model.

Piper carniconnectivum, which is commonly known as "long pepper", is native to Amazon in the northern Brazilian (Yuncker, 1972). A number of compounds have been isolated from this plant including a flavonol ("galangin"), a phenylpropanoid (2-metoxi4,5-metilenodioxipropiofenona), a coumarin known as xanthyletin, three cyclopentenediones and the following four flavonoids: 5-hydroxy-7-methoxy-6-methylflavanone, 5-hydroxy-7-methoxy-8-methylflavanone, 5-hydroxy7-methoxy-6,8-dimethylflavanone and 2'-hydroxy-4',6'dymethoxy-3',5'-dimethylchalcone (Facundo et al., 2004; Facundo \& Braz-Filho, 2004; Facundo et al., 2006).

We assessed the in vitro leishmanicidal activity of DCPC against Leishmania amazonensis. The DCPC showed a leishmanicidal activity against the promastigotes of L. amazonensis, completely inhibiting the replication of the parasites at a concentration of $100 \mu \mathrm{g} / \mathrm{mL}$. A concentration of $50 \mu \mathrm{g} / \mathrm{mL}$ inhibited $99.7 \%$, while at concentrations of $25,12.5$ and $6 \mu \mathrm{g} / \mathrm{mL}$ the levels of inhibition were $98 \%, 71.7 \%$ and $64.4 \%$, respectively (Figure 1). The inhibitory concentrations were calculated to be $4.4 \mu \mathrm{g} / \mathrm{mL}$ (IC50) and $18 \mu \mathrm{g} / \mathrm{mL}$ (IC90). The reference drug Pentamidine completely inhibited the growth of the promastigotes in the first $24 \mathrm{~h}$ at a concentration of $100 \mu \mathrm{g} / \mathrm{mL}$, whereas $0.3 \%$ ethanol had no effect on parasite growth.

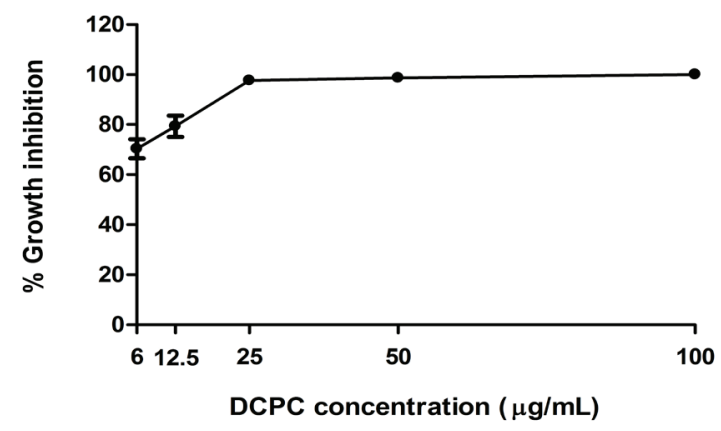

Figure 1. The effect of DCPC on the growth of Leishmania amazonensis promastigotes cultured for $96 \mathrm{~h}$ at concentrations of $6,12.5,25,50$ and $100 \mu \mathrm{g} / \mathrm{mL}$. Assays were performed in duplicate and represent the average of three independent experiments.

The pentamidine is one of drugs for treatment of leishmaniasis and it is used in cutaneous, diffusecutaneous and mucocutaneous leishmaniasis and in visceral leishmaniasis cases resistant to antimonials (Soto-Mancipe et al., 1993). In Brasil, it is the second treatment option for leishmaniasis, but is the first-line 
drug in other countries (Nacher et al., 2001; Lai A Fat et al., 2002; Van der Meide et al., 2009). Like pentavalent antimonials, pentamidine is also highly toxic and has many side effects such as nausea, vomiting, dizziness, headache, hypotension, transient hyperglycemia and hypoglycemia (Neves et al., 2011).

Because of the possibility that active compounds that have therapeutic potential against $L$. amazonensis may be toxic to the host cells (Nakamura et al., 2006), we examined the effect of the DCPC on the viability of peritoneal macrophages from $\mathrm{BALB} / \mathrm{c}$ mice at the same concentrations of DCPC that were used in the promastigote activity assays. The viability of the macrophages at concentrations of $50,25,12.5$ and $6 \mu \mathrm{g} / \mathrm{mL}$ was above $80 \%$ (Figure 2). The $50 \%$ cytotoxic concentration (CC50) in macrophages treated with DCPC was $129 \mu \mathrm{g} / \mathrm{mL}$.

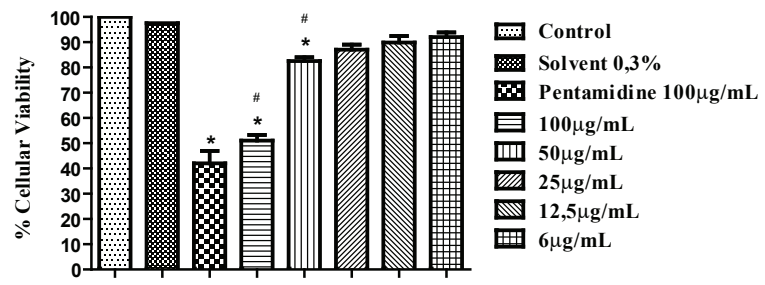

Time (96 h)

Figure 2. The effect of DCPC on the viability of peritoneal macrophages in vitro after $96 \mathrm{~h}$ of treatment. The percentage of viable macrophages was evaluated by trypan blue exclusion. Values represent three independent experiments performed in duplicate. Statistically significant differences $(p<0.05)$ relative to the untreated controls are indicated by $(*)$, and statistically significant differences relative to the solvent are indicated by the symbol (\#).

The cytotoxicity was evaluated using a selectivity index (SI), which is the ratio of the host cell CC50 to the promastigote IC50. According to the SI, DCPC is 29.3 times less toxic to macrophages than to L. amazonensis promastigotes (Table 1). A substance is considered to have promising therapeutic (e.g., leishmanicidal) activity when the resulting SI is greater than 10; however, our results do not eliminate the possibility of adverse side effects in vivo (Cardona, 2006).

The leishmaniasis treatment might be affected by the sensitivity of the causative Leishmania species, gender and age of patients, body localization of lesions, immunological status of the host, treatment schedule and genetic background of parasites (Croft et al., 2002; Decuypere et al., 2012). The conventional treatment is only partially effective against diseases caused by L. braziliensis and L. amazonensis (Croft et al., 2002; Silveira et al., 2004). Moreover, resistance to pentavalent antimonials has been identified for $L$. (L.) donovani in
India and Nepal. In India, $40-60 \%$ of VL patients did not respond to pentavalent antimonial treatment and $25 \%$ were unresponsiveness to pentamidine (Mishra et al., 1992; Jha, 2006). Up to now, the evidence that treatment failure in Brazil is due to parasite primary resistance was not found (Zauli-Nascimento et al., 2010; Monte-Neto et al., 2011).

Table 1. Selectivity index (SI) determined from the CC50 values in murine $(\mathrm{BALB} / \mathrm{c})$ peritoneal macrophages and from the IC50 in Leishmania amazonensis promastigotes.

\begin{tabular}{cccc}
\hline & $\begin{array}{c}\text { Macrophage } \\
\text { CC50 }\end{array}$ & $\begin{array}{c}\text { Promastigotes } \\
\text { IC50 }\end{array}$ & SI \\
\hline DCPC & 129 & 4.4 & 29.3 \\
\hline
\end{tabular}

CC50: Cytotoxic concentration for $50 \%$ of macrophages; IC50 Concentration at which the number of promastigotes is halved; SI: Selectivity index (CC50 (peritoneal macrophages)/IC50 promastigotes).

With the limited supply of drugs used to treat leishmaniasis, the demand for new antileishmanial drugs has intensified. With the increased resistance to pentavalent antimonials, and the second generation drugs (Croft et al., 2006; Decuypere et al., 2012), DCPC may be a tool for the synthesis of new leishmanicidal drugs. The potential of DCPC for treating human leishmaniasis needs further evaluation, to investigate its action on different Leishmania strains, on intracellular amastigotes and/or in animal models.

In conclusion, the cyclopentenedione derivative DCPC, isolated from the roots of Piper carniconnectivum, inhibited the growth of $L$. amazonensis promastigotes with an IC50 of $4.4 \mu \mathrm{g} / \mathrm{mL}$ without affecting macrophage viability at concentrations up to $50 \mu \mathrm{g} / \mathrm{mL}$. These results indicate, for the first time, that DCPC is a promising molecule for studies investigating the development of leishmanicidal drugs.

\section{Acknowledgements}

We thank the Conselho Nacional de Desenvolvimento Científico e Tecnológico.

\section{References}

Abreu-Silva AL, Calabrese KS, Tedesco RC, Mortara RA, Gonçalves da Costa SC 2003. Central nervous system involvement in experimental infection with Leishmania (Leishmania) amazonensis. Am J Trop Med Hyg 68: 661-665.

Agra MF, Freitas PF, Barbosa-Filho JM 2007. Review of the medicinal and poisonous plants in the Northeast of Brazil. Rev Bras Farmacogn 17: 114-140.

Agra MF, Silva KN, Basilio IJLD, França PF, Barbosa-Filho JM 2008. Survey of medicinal plants used in the Northeast region of Brazil. Rev Bras Farmacogn 18: 
472-508

Amato VS, Padilha ARS, Nicodemo AC, Duarte MIS, Valentini M, Uip DE, Boulos M, Amato VN 2000. Use of itraconazole in the treatment of mucocutaneous Leishmaniasis: A pilot study. Int J Infect Dis 4: 153157.

Babu KS, Li XC, Jacob MR, Zhang Q, Khan SI, Ferreira D, Clark AM 2006. Synthesis, antifungal activity, and structure activity relationships of coruscanone A analogs. J Med Chem 49: 7877-7886.

Barral A, Pedral Sampaio D, Grimaldi Jr G, Momem HMC, Mahon-Pratt D, Jesus A, Almeida R, Badaró R, Barral-Netto M, Carvalho EM, Johnson Jr WD 1991. Leishmaniasis in Bahia, Brazil: evidence that Leishmania amazonensis produces a wide spectrum of clinical disease. Am J Trop Med Hyg 44: 536-546.

Bezerra DP, Militão GCG, Castro FO, Pessoa C, Moraes MO, Silveira ER, Lima MAS, Elmiro MJF, CostaLotufo LV 2007. Piplartine induces the inhibition of leukemia cell proliferation, triggering both apoptosis and necrosis pathways. Toxicol in Vitro 21: 1-8.

Calderon LA, Silva-Jardim I, Zuliani JP, Silva AA, Ciancaglini P, Pereira da Silva LH, Stabeli RG 2009. Amazonian biodiversity: a view of drug development for Leishmaniasis and Malaria. J Braz Chem Soc 20: 1011-1023.

Cardona W, Quinones W, Robledo S, Velez I, Murga J, GarciaFortanet J, Carda M, Cardona D, Echeverri F 2006. The antiparasitic and antimycobacterial activity of passifloricin analogues. Tetrahedron 62: 4086-4092.

Coelho LIC, Paes M, Guerra JA, Barbosa MG, Coelho C, Lima B, Brito ME, Brandão-Filho SP 2011. Characterization of Leishmania spp. causing cutaneous leishmaniasis in Manaus, Amazonas, Brazil. Parasitol Res 108: 671-677.

Croft SL, Yardley V 2002. Chemotherapy of Leishmaniasis. Curr Pharm Design 8: 319-342.

Croft SL, Coombs GH 2003. Leishmaniasis: current chemotherapy and recent advances in the search for novel drugs. Trends Parasitol 19: 502-508.

Croft SL, Sundar S, Fairlamb AH 2006. Drug resistance in leishmaniasis. Clin Microbiol Rev 19: 111-126.

Decuypere S, Vanaerschot M, Brunker K, Imamura H, Müller S, Khanal B, Rijal S, Dujardin JC, Coombs GH 2012. Molecular mechanisms of drug resistance in natural leishmania populations vary with genetic background. Plos Neglect Trop D 6: e1514.

Dias LC, Shimokomaki SB, Shiota RT 2005. Short synthesis of a new cyclopentene-1,3-dione derivative isolated from Piper carniconnectivum. J Braz Chem Soc 16: 482-489.

Facundo VA, Sá AL, Silva SAF, Morais SM, Matos CRR, BrazFilho R 2004. Three new natural cyclopentenedione derivatives from Piper carniconnectivum. J Braz Chem Soc 15: 140-145.
Facundo VA, Braz-Filho R 2004. C-methylated flavonoids from the roots of Piper carniconnectivum C. DC. (Piperaceae). Biochem Syst Ecol 32: 1215-1217.

Facundo VA, Rezende CM, Pinto AC 2006. Essential oil from Piper carniconnectivum C. CD. leaves and stems. $J$ Essent Oil Res 18: 296-297.

Ferreira MGPR, Kayano AM, Silva-Jardim I, Silva TO, Zuliani JP, Facundo VA, Calderon LA, Almeida-e-Silva A, Ciancaglini P, Stabeli RG 2010. Antileishmanial activity of 3-(3,4,5-trimethoxyphenyl) propanoic acid purified from Amazonian Piper tuberculatum Jacq. (Piperaceae) fruit. Rev Bras Farmacogn 20: 10031006.

Gordon S, Unkeless JC, Cohn ZA 1974. Induction of macrophage plasminogen activation and phagocytosis by endotoxin stimulation: evidence for a two-stage process. J Exp Med 140: 995-1010.

Gramiccia M, Gradoni L 2005. The current status of zoonotic leishmaniases and approaches to disease control. Int $J$ Parasitol 35: 1169-1180.

Hermoso A, Jimenez IA, Mamani ZA, Bazzocchi IL, Pinero JE, Ravelo AG, Valladares B 2003. Antileishmanial activities of dihydrochalcones from Piper elongatum and related synthetic compounds. Structural requirements for activity. Bioorgan Med Chem 11: 3975-3980.

Herwaldt BL 1999. Leishmaniasis. Lancet 354: 1191-1199.

Jha TK 2006. Drug unresponsiveness \& combination therapy for kala-azar. Indian J Med Res 123: 389-398.

Lai A Fat EJ, Vrede MA, Soetosenojo RM, Lai A Fat RF 2002. Pentamidine, the drug of choice for the treatment of cutaneous leishmaniasis in Surinam. Int $J$ Dermatol 41: 796-800.

Li XC, Jacob MR, Wedge D 2006. Cyclopentenedione antifungal compounds and methods for their use. USA-Patent 7109380.

Lima EB, Porto C, Motta JOC, Sampaio RNR 2007. Treatment of American cutaneous leishmaniasis. An Bras Dermatol 82: 111-124.

Lucas CM, Franke ED, Cachay MI, Tejada A, Cruz ME, Kreutzer RD, Barker DC, MCcann SHE, Watts DM 1998. Geographic distribution and clinical description of leishmaniasis cases in Peru. Am J Trop Med Hyg 59: 312-317.

Mishra M, Biswas UK, Jha DN, Khan AB 1992. Amphotericin versus pentamidine in antimony-unresponsive kalaazar. Lancet 340: 1256-1257.

Monte-Neto RL, Coelho AC, Raymond F, Légaré D, Corbeil J, Melo MN, Frézard F, Ouellette M 2011. Gene expression profiling and molecular characterization of antimony resistance in Leishmania amazonensis. Plos Neglect Trop D 5: e1167.

Morrison B, Mendoza I, Delgado D, Reyes Jaimes O, Aranzazu N, Paniz-Mondolfi AE. 2009. Diffuse (anergic) cutaneous leishmaniasis responding to amphotericin 
B. Clin Exp Dermatol 35: e116-e119.

Nacher M, Carme B, Sainte Marie D, Couppié P, Clyti E, Guibert P, Pradinaud R 2001. Influence of clinical presentation on the efficacy of a short course of pentamidine in the treatment of cutaneous leishmaniasis in French Guiana. Ann Trop Med Parasit 95: 331-336.

Nakamura CV, Santos AO, Vendrametto MC, Luize PS, Dias Filho BP, Cortez DAG, Ueda-Nakamura T 2006. Antileishmanial activity of a hydroalcoholic extract and the fractions obtained from leaves of Piper regnellii (Miq.) C. DC. var. pallescens (C. DC.). Rev Bras Farmacogn 16: 61-66.

Neves LO, Talhari AC, Gadelha EPN, Silva-Junior RM, Guerra JAO, Ferreira LCL, Talhari S 2011. A randomized clinical trial comparing meglumine antimoniate, pentamidine and amphotericin B for the treatment of cutaneous leishmaniasis by Leishmania guyanensis. An Bras Dermatol 86: 1092-1101.

Oliveira LF, Schubach AO, Martins MM, Passos SL, Oliveira RV, Marzochi MC, Andrade CA. 2011. Systematic review of the adverse effects of cutaneous leishmaniasis treatment in the New World. Acta Trop 118: 87-96.

Parmar VS, Jain SC, Bisht KS, Jain R, Taneja R, Jha A, Tuagi OD, Prasad AK, Wengel J, Olesen CE, Boll PM 1997. Phytochemistry of the genus Piper. Phytochemistry 46: 597-673.

Rodrigues RV, Lanznaster D, Longhi Balbinot DT, Gadotti VM, Facundo VA, Santos ARS 2009. The antinociceptive effect of crude extract, fractions and three alkaloids obtained from the fruit of Piper tuberculatum. Biol Pharm Bull 32: 1809-1812.

Silveira FT, Lainson R, Corbett CEP. 2004. Clinical and immunopathological spectrum of American cutaneous leishmaniasis with special reference to the disease in Amazonian Brazil - A review. Mem I Oswaldo Cruz 99: 239-251.

Singh N 2006. Drug resistance mechanisms in clinical isolates of Leishmania donovani. Indian J Med Res 123: 411-422.

Soto-Mancipe J, Grogl M, Berman JD 1993. Evaluation of pentamidine for the treatment of cutaneous leishmaniasis in Colombia. Clin infect Dis 16: 417425.

Tolezano JE, Uliana SR, Taniguchi HH, Araújo MF, Barbosa JA, Barbosa JE, Floeter-Wiinter LM, Shaw JJ 2007. The first records of Leishmania (Leishmania) amazonensis in dogs (Canis familiaris) diagnosed clinically as having canine visceral leishmaniasis from Araçatuba County. Vet Parasitol 149: 280-284.

Van der Meide WF, Sabajo LO, Jensema AJ, Peekel I, Faber WR, Schallig HD, Lai A Fat RFM 2009. Evaluation of treatment with pentamidine for cutaneous leishmaniasis in Suriname. Int J Dermatol 48: 52-58.

WHO (World Health Organization) 2010. The control of leishmaniasis: report from the meeting of the WHO Expert Committee on the Control of Leishmaniases. Technical report series no. 949. Geneva.

Yuncker TG 1972. The Piperaceae of Brazil. Hoehnea 2: 19366.

Zauli-Nascimento RC, Miguel DC, Yokoyama-Yasunaka JK, Pereira LI, Pelli de Oliveira MA, Ribeiro-Dias F, Dorta ML, Uliana SR 2010. In vitro sensitivity of Leishmania (Viannia) braziliensis and Leishmania (Leishmania) amazonensis Brazilian isolates to meglumine antimoniate and amphotericin B. Trop Med Int Health 15: 68-76.

Zerpa O, Ulrich M, Blanco B, Polegre M, Ávila A, Matos N, Mendoza I, Pratlong F, Ravel C, Convit J 2007. Diffuse cutaneous leishmaniasis responds to miltefosine but then relapses. Brit J Dermatol 156: 1328-1335.

\section{*Correspondence}

Izaltina Silva_Jardim

Laboratório de Cristalografia de Proteínas e Biologia Estrutural, Departamento de Física e Informática, Instituto de Física de São Carlos, Universidade de São Paulo

Av. Trabalhador São-carlense, 400, Caixa Postal 369, 13566590 São Carlos-SP, Brazil

izaltina@ursa.ifsc.usp.br

Tel.: 55 (16) 3373-9868

Fax: 55 (16) 3373-9881 